\title{
Jornalismo e ideologia da cultura: Os conflitos entre indígenas e ruralistas em Mato Grosso do Sul ${ }^{\mathrm{a}}$
}

\section{Journalism and ideology of culture: The conflicts between indigenous people and rural producers in Mato Grosso do Sul}

\author{
MARCOS PA ULO DA STLVA \\ Universidade Federal de Mato Grosso do Sul, Programa de Pós-Graduação em Comunicação. Campo \\ Grande - MS, Brasil \\ M A URÍCIO DE MELO RA POS O \\ Pontifícia Universidade Católica de Minas Gerais, Programa de Pós-Graduação em Ciências Sociais. \\ Belo Horizonte - MG, Brasil
}

\section{RESUMO}

$\mathrm{O}$ artigo busca compreender a construção do enquadramento dos fatos que envolvem conflitos entre etnias indígenas e produtores rurais no principal jornal impresso de Mato Grosso do Sul, o Correio do Estado, adotando-se como ponto de referência o assassinato do líder indígena Semião Vilhalva, das etnias Guarani e Kaiowá, em agosto de 2015. A partir do referencial teórico da framing analysis, volta-se a um recorte empírico de cinco editoriais e de cinco artigos de opinião veiculados entre agosto e outubro de 2015, identificando-se na retórica contemporânea do veículo elementos simbólicos e culturais afeitos à "ideologia da cultura sul-mato-grossense”, concepção forjada pelas elites regionais desde a década de 1930. Palavra-chave: Enquadramento jornalístico, Mato Grosso do Sul, Correio do Estado, conflitos entre indígenas e produtores rurais

\section{ABSTRACT}

The article intends to understand fact-framing about conflicts between indigenous ethnic groups and rural producers in Correio do Estado, the main Mato Grosso do Sul state newspaper, adopting as a reference point the murder of the indigenous leader Semião Vilhalva, from the Guarani and Kaiowá ethnic groups, in August 2015. From the theoretical perspective of framing analysis, five editorials and five opinion articles published from August to October 2015 are studied as an empirical basis, identifying, in the newspaper's contemporary rhetoric, symbolic and cultural elements related to the "ideology of the Mato Grosso do Sul culture", a concept forged by regional elites since the 1930s.

Keywords: Journalistic framing, Mato Grosso do Sul, Correio do Estado, conflicts between indigenous people and rural producers

DOI:http://dx.doi.org/10.11606/issn.1982-8160.v15i1 p249-274

V.15 - № 1 jan./abr. 2021 São Paulo - Brasil SILVA I RAPOSO p. 249-274
${ }^{a} \mathrm{O}$ presente trabalho foi realizado com apoio da Coordenação de Aperfeiçoamento de Pessoal de Nível Superior - Brasil (Capes) - código de financiamento 001.

${ }^{\mathrm{b}}$ Professor do Programa de Pós-Graduação em Comunicação e do Curso de Jornalismo da Universidade Federal de Mato Grosso do Sul. Orcid: http://orcid.org/00000003-2868-4865. E-mail: silva_mp@uol.com.br

${ }^{c}$ Doutorando em Ciências Sociais pela Pontifícia Universidade Católica de Minas Gerais. Mestre em Comunicação pela Universidade Federal de Mato Grosso do Sul (UFMS). Orcid: https://orcid.org/00000001-6211-997X. E-mail: mauraposo@hotmail.com 


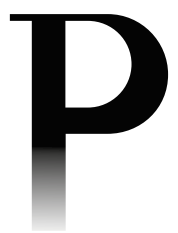

${ }^{1}$ Os conflitos entre fazendeiros e indígenas arrastam-se há décadas em Mato Grosso do Sul. Em um plano mais recente, para efeitos de contextualização, um confronto entre indígenas e policiais em 2013 durante a reintegração de posse de uma fazenda ocupada em Sidrolândia, a 70 quilômetros de Campo Grande, deixou um indígena terena morto e vários outros feridos. A partir do ocorrido, com o acirramento dos ânimos na região, ocorreu uma mobilização federal para a criação de tentativas de mediações entre fazendeiros e o movimento indígena no estado, reforçando o conflito de versões. No campo político, duas Comissões Parlamentares de Inquérito na Assembleia Legislativa do estado de Mato Grosso do Sul refletiram em 2016 a disputa de posições: uma sobre o Conselho Indigenista Missionário (Cimi), entidade ligada à Igreja Católica, e outra sobre o genocídio indígena. Em âmbito nacional, a Comissão Parlamentar de Inquérito (CPI) da Funai-Incra, dominada por parlamentares da bancada ruralista, gerou relatório de 3.385 páginas, apresentado em junho de 2017, no qual se sugere o indiciamento de diretores de entidades que defendem a causa indígena, de antropólogos e de integrantes do Ministério Público Federal, além de pessoas denominadas de "falsos indígenas". No campo jurídico, tramita a Proposta de Emenda à Constituição (PEC)

71 , que permite a indenização de possuidores de títulos relativos a terras declaradas como indígenas expedidos até o dia 5 de outubro de 1988. Além disso, até o final de 2018 tramitava a PEC 215, que transferiria ao Congresso o poder das demarcações de terras da Fundação Nacional do Índio (Funai). Todavia, a primeira Medida Provisória

\section{INTRODUÇÃO}

S DISPUTAS QUE ocorrem entre os diferentes grupos sociais pela
definição e pela interpretação da realidade transbordam para as diver-
sas manifestações do espaço público e demandam legitimação social. Desde o século XIX, os jornais assumiram a responsabilidade de veicular e de disseminar narrações do cotidiano, tornando-se, consequentemente, palco de debates nos quais se passou a construir, conformar e alimentar a opinião pública (Gomes, 2009). Para a consecução de seus objetivos, os mais diferentes grupos sociais passaram a engajar-se na formação e na aprovação desta opinião - ou, em outros termos, na disputa pela hegemonia cultural, política, econômica e social.

No que tange ao contexto deste estudo, entre os anos de 1985 e 2014 foram registrados 947 homicídios de indígenas no Brasil, sendo 420 dessas ocorrências em Mato Grosso do Sul. Pelo menos um em cada dois casos de assassinatos de indígenas registrados no país entre 2003 e 2014 aconteceu no estado, o que indica que o território sul-mato-grossense concentrou no período $54,8 \%$ das mortes de indígenas brasileiros (Conselho Indigenista Missionário [Cimi], 2016). No dia 29 de agosto de 2015, mais um caso significativo engrossou as estatísticas: foi assassinado Semião Fernandes Vilhalva, de 24 anos, membro das etnias Guarani e Kaiowá, no município de Antônio João, localizado a 283 quilômetros ao sul da capital, Campo Grande. A morte ocorreu após os produtores rurais da região se reunirem na sede do sindicato rural e decidirem retomar, utilizando-se de seus próprios meios, uma fazenda ocupada pelos indígenas, acarretando uma situação de conflito representativa para os parâmetros regionais - o que foi expresso por meio de "narrações jornalísticas” (Sodré, 2009).

$\mathrm{O}$ episódio relatado pode ser tratado como um acontecimento no sentido sociológico do conceito. Segundo Martins (2010), o acontecimento é "um adensamento problemático" (p. 137) de contradições socioculturais e históricas. Constitui, ainda, um "ponto de reparo metodológico" (p. 138) a partir do qual o pesquisador arguto pode compreender a dinâmica da sociedade. Outrossim, se os assassinatos podem ser entendidos como acontecimentos na acepção sociológica, do ponto de vista comunicacional trata-se também - no caso em crivo - de um acontecimento jornalístico (Gomes, 2009; Sodré, 2009) que tomou as páginas dos veículos midiáticos.

No plano contextual, os conflitos entre produtores rurais e etnias indígenas no estado de Mato Grosso do Sul têm gerado nas últimas décadas uma série de repercussões sociais, políticas e jurídicas. Diversos grupos têm se mobilizado em torno da definição e da compreensão da natureza, das causas e dos sujeitos envolvidos, assim como da proposição de soluções para a contenda ${ }^{1}$. Essa 
disputa de posições também se revela um conflito simbólico pela conquista de legitimidade social ${ }^{2}$. Parte dessas manifestações se dá nos meios de comunicação, não apenas por intermédio das notícias, mas ainda a partir da opinião publicada por meio de artigos assinados por membros da sociedade civil e de editoriais que explicitam as opiniões dos veículos.

Com base no entendimento da concepção de acontecimento como uma manifestação de contradições imanentes às estruturas sociais, compreende-se que os modos de expressão instituídos pelo jornalismo no imediato do cotidiano e da vivência histórica não estão imunes às várias representações de mundo em disputa, bem como - e por conseguinte - à decisão não apenas do que fará parte da história, mas como e quem serão seus protagonistas na narração dos fatos. Nesse cenário, este estudo pretende investigar a relação entre elementos culturais e ideológicos e o conteúdo opinativo veiculado no principal jornal impresso de Mato Grosso do Sul, o Correio do Estado ${ }^{3}$, que no período referente ao recorte empírico da pesquisa apresentou um enfático tratamento jornalístico voltado aos conflitos entre etnias indígenas e produtores rurais. O ponto nevrálgico da pesquisa ancora-se no contexto segundo o qual o conteúdo opinativo veiculado no periódico aciona referenciais simbólicos e culturais afeitos à "ideologia da cultura sul-mato-grossense" (Banducci, 2009, p. 107), concepção forjada historicamente em manifestações que remetem à década de 1930, dezenas de anos antes do processo oficial de desmembramento e criação do estado.

\section{MÉTODO E RECORTE EMPÍRICO}

Propõe-se na pesquisa investigar manifestações que definem o enquadramento das representações, dos valores, das ambiguidades, das contradições e das tendências, assim como dos personagens presentes nas narrativas de natureza opinativa, a respeito do que se convencionou a chamar no meio jornalístico de conflitos entre indígenas e produtores rurais. Em função do tipo de investigação, opta-se pela técnica de amostragem entendida como a seleção de dados de dimensão e de composição representativa de acordo com o objeto da pesquisa a "amostragem sistemática não probabilística de representatividade social" (Lopes, 2005, p. 145), que culmina na seleção de conteúdo jornalístico durante os meses de agosto, setembro e outubro de 2015 a partir do tema mencionado.

Adota-se como ponto central de observação das publicações o citado caso do assassinato do indígena Semião Fernandes Vilhalva, dos povos Guarani e Kaiowá, em Antônio João, no dia 29 de agosto de 2015. Do ponto de vista metodológico, o evento é a objetivação de um ponto de reparo em que se manifesta a culminância das contradições sociais que se revelam enquanto problema
(MP) 870/2019 editada por Jair Bolsonaro após assumir o governo federal em 1 de janeiro de 2019 passou para o Ministério da Agricultura a atribuição de identificar, delimitar e demarcar terras indígenas e quilombolas.

${ }^{2}$ Convém mencionar que, no bojo das disputas simbólicas por legitimidade social, o setor ruralista tem se articulado política e economicamente desde a última década, em nível regional e nacional, para formular e difundir uma retórica de promoção da chamada Cultura Agro, o que inclui a compra de espaços publicitários e a criação de canais próprios de televisão e internet, entre outras estratégias.

${ }^{3} \mathrm{O}$ jornal Correio do Estado foi fundado em fevereiro de 1954 com o intuito político de defender e eleger para governador de Mato Grosso o candidato Fernando Corrêa da Costa (União Democrática Nacional - UDN), seu fundador inicial, que se contrapunha politicamente a Filinto Müller, do Partido da Social Democrata (PSD). O veículo nasceu, por conseguinte, com forte orientação política vinculado à UDN, agremiação de ênfase conservadora. Mesmo com a mudança de propriedade do jornal, que posteriormente passou a ser administrado por José Barbosa Rodrigues, a pauta política nunca saiu do horizonte do periódico. No âmbito nacional, por exemplo, o veículo foi favorável à presença dos militares no poder após abril de 1964, acontecimento noticiado como "A revolução moralizadora que salvou esse país”. Anos mais tarde, o Correio do Estado militou em favor da divisão de Mato Grosso e a criação de Mato Grosso do Sul (Dal Moro, 2012). Ativo desde sua fundação, o jornal é um dos 


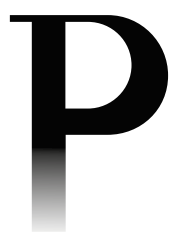

três mais antigos ainda em circulação em Mato Grosso do Sul. Pertencente atualmente ao empresário Antonio João Hugo Rodrigues, com ativa atuação política no estado (foi candidato a deputado estadual pelo Partido Trabalhista

Cristão [PTC], em 2018, e a senador pelo PSD, em 2014), o jornal integra o grupo Correio do Estado de Comunicação, do qual fazem parte também a TV

Campo Grande (atualmente denominada SBT-MS, como afilhada ao Sistema Brasileiro de Televisão), a rádio FM Mega 94, o site de notícias Correio do Estado e a Fundação Barbosa Rodrigues. O jornal impresso é estruturado em editorias fixas, como Política, Economia, Cidades, Esportes, Brasil, Mundo e Correio B, e editorias esporádicas, que aparecem somente em algumas edições. De acordo com o Instituto Verificador de Circulação (IVC), o veículo tem tiragem média de 12 mil exemplares e atinge todas as regiões do estado.

\footnotetext{
${ }^{4}$ Para efeitos deste estudo, considerando as limitações de espaço intrínsecas do artigo e a recorrência de argumentos presentes nos textos, o que garante a exaustividade como validação da amostra, optou-se para fins metodológicos pela adoção de um recorte empírico equitativo entre editoriais e colunas.
}

comunicacional, uma vez que enseja a produção de uma variedade de expressões midiáticas: notícias, editoriais, comentários, charges e artigos de opinião. Do ponto de reparo, procedeu-se à leitura retrospectiva dos exemplares publicados de modo a identificar o início da cobertura jornalística da série de eventos que levou ao desfecho trágico do dia 29 de agosto de 2015 - isto é, numa sequência retroativa, ocorreu a identificação de quando a temática passou a receber a atenção da cobertura jornalística do veículo, o que revela a assimilação da tensão no sul do estado pela pauta noticiosa, aportando-se no dia 19 de julho de 2015. Em seguida, acompanharam-se as publicações realizadas após o ponto central até quando os fatos e eventos correlacionados deixaram de figurar no jornal analisado, o que ocorreu no dia 15 de outubro de 2015.

Dos 76 exemplares do Correio do Estado que circularam no período (considerando que o veículo não circula aos domingos), 35 (ou 47\%) contêm itens informativos (notícias, notas e reportagens) atinentes à temática indígena, aos conflitos de terra e à identidade regional; e vinte contêm itens opinativos - ou opiniões publicadas (Gomes, 2009) -, o que remete a 27\% de recorrência para efeitos da pesquisa. Isso significa que, aproximadamente, para cada dois exemplares que veicularam itens informativos no período, um veiculou ao menos um item opinativo. Para efeitos deste artigo, todavia, o corpus de análise qualitativa é composto por dez itens opinativos identificados no jornal Correio do Estado no período em crivo; a saber: cinco editoriais (a totalidade veiculada no período) e os primeiros cinco artigos de opinião veiculados no recorte (o que compreende um intervalo temporal de vinte dias entre 28 de agosto de 2015 - véspera do assassinato do indígena Semião Vilhalva - e 16 de setembro de 2015) ${ }^{4}$. Como critério de identificação e seleção do material da pesquisa, embora se reconheça a artificialidade epistêmica da divisão entre informação e opinião (Chaparro, 2008), adota-se para fins metodológicos a classificação de gêneros e de formatos jornalísticos elaborada por Melo e Assis (2010). Entre os formatos opinativos, são analisados editoriais, artigos e colunas. Estes dois últimos são tratados em conjunto por constituírem, ambos, textos de opinião de membros da sociedade civil, assinados pelos autores, e que, para efeitos formais, não traduzem necessariamente a opinião do jornal.

De outra parte, a abordagem metodológica ampara-se na concepção de enquadramento jornalístico - ou framing -, conforme as perspectivas de Entman (1991, 1993), Gitlin (2003) e Kuypers (2009) a partir do conceito original de Goffman (2012). De acordo com Entman (1993), o enquadramento jornalístico acontece em pelo menos quatro locais no processo de comunicação: no comunicador, no texto, no receptor e na cultura. Centra-se aqui nos aspectos do texto, na ausência e na presença de palavras-chave, frases, imagens estereotipadas e 
fontes de informação, e em sua relação com a cultura, enquanto instância na qual se encontra o estoque de quadros primários acionados (Carvalho, 2009; Goffman, 2012). Entende-se que os referentes primários têm sua origem, significação e ressignificação em articulações simbólicas que disputam os sentidos do mundo e são expressões das diferenças e das desigualdades da realidade sociocultural: tal como a questão da ideologia da cultura sul-mato-grossense, abordada neste estudo.

Em relação à operacionalização do conceito de enquadramento, Entman (1993) propõe uma definição que envolve essencialmente ações de seleção e de saliência. Enquadrar, para o autor, "é selecionar alguns aspectos de uma realidade percebida e torná-los mais salientes em um texto comunicacional"' (p. 52), de modo a oferecer quatro funções: "promover uma definição de problema particular, interpretação causal, avaliação moral e/ou recomendação de tratamento para o item descrito" ${ }^{6}$ (p. 52). Prossegue o sociólogo:

Os quadros, então, definem problemas - determinam o que um agente causal está fazendo com quais custos e benefícios, geralmente medidos em termos de valores culturais comuns; diagnosticam causas - identificam as forças que criam o problema; fazem julgamentos morais - avaliam agentes causais e seus efeitos; $\mathrm{e}$ sugerem soluções - oferecem e justificam tratamentos para os problemas e preveem seus efeitos prováveis ${ }^{7}$. (p. 52)

Uma única sentença de determinado texto pode executar mais de uma dessas quatro funções, mas muitas sentenças podem não executar nenhuma, não sendo preciso, portanto, que o enquadramento inclua necessariamente todas elas. Com base nessa perspectiva, do ponto de vista operacional, busca-se nas publicações que compõem o recorte empírico deste estudo a atenção aos quatro elementos-chave da construção dos argumentos mencionados por Entman (1993), isto é: a) definição do problema; b) diagnóstico de causas; c) julgamentos morais, e d) proposições de soluções. Na prática, ao longo da análise dos editoriais e das colunas do Correio do Estado, as funções de enquadramento propostas pelo sociólogo estadunidense serão recuperadas e identificadas por meio de suas respectivas letras (a, b, c, d) e sistematizadas em quadros como forma de desvelamento dos recursos argumentativos mobilizados. A abordagem se aproxima, por conseguinte, da percepção de Kuypers (2009), segundo a qual "a análise de enquadramento pode ser usada para melhor entender qualquer peça retórica" (p. 182) da comunicação midiática. Parte-se agora para a apresentação do contexto histórico que ilumina a situação a ser analisada.

V.15 - № 1 jan./abr. 2021 São Paulo - Brasil SILVA I RAPOSO p. 249-274
${ }^{5}$ No original: "is to select some aspects of a perceived reality and make them more salient in a communicating text". Esta e demais traduções, dos autores.

${ }^{6}$ No original: "to promote a particular problem definition, causal interpretation, moral evaluation, and/or treatment recommendation for the item described".

${ }^{7}$ No original: "Frames, then, define problems - determine what a causal agent is doing with what costs and benefits, usually measured in terms of common cultural values; diagnose causes - identify the forces creating the problem; make moral judgments evaluate causal agents and their effects; and suggest remedies offer and justify treatments for the problems and predict their likely effects".

${ }^{8}$ No original: "framing analysis can be used to better understand any rhetorical artifact".

MATRIZes 


\section{A IDEOLOGIA DA CULTURA SUL-MATO-GROSSENSE}

No dia 11 de outubro de 1977, o então presidente da República, general Ernesto Geisel, assinou o decreto que criava o estado de Mato Grosso do Sul. Antes de significar a apoteose da trajetória dos desejos dos habitantes da porção meridional do grande estado de Mato Grosso, a secessão foi consequência do pragmatismo político exógeno, mais uma estratégia que visava à manutenção dos militares no poder central em Brasília (Amarilha, 2006). Até 1979, os elementos tangíveis de definição do novo estado da federação estavam colocados: território, sede administrativa, poderes Legislativo, Judiciário e Executivo. No entanto, os elementos simbólicos em torno dos quais a população pudesse se identificar ainda estavam por se definir. Criar um hino, um brasão e uma bandeira eram tarefas relativamente mais simples, mas ainda faltava algo essencial: uma identidade histórico-cultural que singularizasse Mato Grosso do Sul entre os demais estados da federação.

Entraram em cena, assim, os homens de letras. Na consolidação da nova unidade federativa, ensejou-se o projeto de sistematizar, selecionar e divulgar uma história própria de Mato Grosso do Sul. Nesse cenário, os membros da Academia de Letras e História de Campo Grande (ALH-CG, fundada em 1972), investidos de seus poderes simbólicos, fundaram, em 1978, o Instituto Histórico e Geográfico de Mato Grosso do Sul (IHG-MS) e a Academia SulMato-Grossense de Letras (ASL), entidades coirmãs. Uma série de esforços foi empenhada nessas agremiações na construção de "uma história que contemple e contenha o Estado de Mato Grosso do Sul como um todo" (Amarilha, 2006, p. 177) e de uma identidade sul-mato-grossense que justificasse a existência de um ser do sul, suficientemente diferente dos povos do norte. Todo esse trabalho, de acordo com Banducci (2009), "visava ao mesmo tempo encontrar referências genuínas e construir um núcleo de significados que desse consistência simbólica ao novo contexto cultural que, se a partir daquele momento começava a ganhar forma, mantinha-se vinculado ao antigo conteúdo" (pp. 107-108).

Sob a ótica da antropologia cultural, Banducci (2009) defende que a construção simbólica que se seguiu à secessão de Mato Grosso erigiu-se sobre uma revisão ou seleção histórica de elementos singularizantes da trajetória da porção meridional do grande estado mato-grossense. Soma-se a isso um novo discurso identitário, construído nos anos que se seguiram à criação de Mato Grosso do Sul, ligados à temática ambiental, de revalorização do pantanal e dos personagens pantaneiros. Amarilla (2006) e Queiroz (2006), por sua vez, seguem pormenorizadamente a trilha do que Banducci (2009) denomina de "antigo conteúdo" da elaboração identitária do sul-mato-grossense. Constituem-se formulações sistemáticas de intelectuais, ligados ou oriundos 
da elite política e econômica do sul do antigo Mato Grosso, principalmente, da chamada "geração de 1930".

Para os efeitos deste estudo, não se pretende problematizar a discussão sobre a identidade sul-mato-grossense em $\mathrm{si}^{9}$, mas servir-se de seu escopo para a reflexão posterior sobre a relação das opiniões publicadas no principal jornal regional e suas eventuais ligações com tais discursos identitários, estabelecendo os enquadramentos sobre os conflitos entre indígenas e produtores rurais. Para tanto, partilha-se com Banducci (2009) o pressuposto de que "a construção da identidade de um povo é um processo não apenas dinâmico e segmentado, mas contraditório e ideológico, na medida em que se constitui num esforço por justificar, racionalizar e legitimar diferenças internas" (p. 108).

O denominado antigo conteúdo é bem exemplificado nas construções dos grupos divisionistas da década de 1930. Somente naquele período emergiu um pensamento sistemático e militante que defendia claramente a divisão de Mato Grosso (Bittar, 2009). As primeiras sistematizações sobre uma identidade sul-mato-grossense se estabeleceram em oposição ao discurso dos intelectuais cuiabanos que projetaram, nas duas primeiras décadas do século XX, uma reelaboração positiva das representações do povo mato-grossense. Segundo Queiroz (2006), pode-se dividir os elementos históricos da constituição do discurso identitário em dois blocos de representações: o primeiro, formado por uma redistribuição interna dos estigmas atribuídos ao povo de Mato Grosso, o que significa atribuir aos povos do centro e do norte do estado as velhas representações negativas; e o segundo, que se constitui de apropriações e de transformações da identidade mato-grossense formulada, principalmente no âmbito do Instituto Histórico e Geográfico de Mato Grosso, a partir de 1919. Com essas operações de deslocamento e de ressignificação retórica, as formulações engendradas pelos intelectuais do sul do estado estabeleceram uma identidade de contraste que almejava demarcar limites entre o nós e o eles, aqui significando, respectivamente, os mato-grossenses do sul e os mato-grossenses do centro e do norte.

A partir da ascensão econômica do sul de Mato Grosso nas primeiras décadas do século XX, surgiram as reivindicações separatistas mais contundentes das elites locais. Durante as décadas de 1920 e 1930 passou a ser gestada a chamada "geração de 1930" (Bittar, 2009), que apresentou as primeiras sistematizações das reivindicações de secessão de Mato Grosso nos documentos produzidos pela Liga Sul-mato-grossense, fundada por jovens que estudavam no Rio de Janeiro, filhos das elites do sul do estado. Erigiu-se, assim, os alicerces de uma identidade contrastiva pela qual se buscava saber o que se é a partir da negação daquilo que pertence ao outro. Concernente ao primeiro bloco de representações, o que
${ }^{9}$ Não há neste trabalho a intenção precípua de fazer uma abordagem específica das construções identitárias, oferecendo um contraponto discursivo e crítico, mas, tão somente, apresentá-las como hipotéticos marcos de referência primários que alimentam as construções midiáticas, observando os passos teórico-metodológicos adotados. 
se revela é uma verdadeira campanha iconoclasta contra tudo que se referia à Cuiabá e aos povos do norte e do centro do estado. As pechas de atrasado e decadente tornam-se atributos dos nortistas. Desde as técnicas de criação de gado até a falta de ímpeto industrial, passando pela desqualificação da cidade de Cuiabá, constituem-se os elementos inferiorizantes atribuídos ao norte em relação ao sul. Um dos documentos da década de 1930 da Liga Sul-matogrossense chega a ridicularizar o então General Rondon por este acreditar que, segundo os separatistas,

Amar verdadeiramente o Estado é considerar Cuiabá a melhor cidade do mundo, o rio Cuiabá um paraíso, embasbacar-se na grandiosidade das florestas nortistas, deliciar-se com danças inocentes de Nhambiquaras e caçadas valentes de Bororós, gozar histórias de montanhas de ouro e diamantes. (A divisão de Mato Grosso..., 1934, citado por Queiroz, 2006, p. 62)

Desse trecho, destaca-se a referência depreciadora das matrizes e práticas culturais indígenas, marcando, de forma enfática, a dicotomia entre uma suposta cultura nativa inferior e, como ficará claro mais adiante, a cultura sobreposta modernizante e civilizada. A um só tempo estabelecem, portanto, uma alteridade em que o elemento indígena define o que os sul-mato-grossenses não se constituem. Por outro lado, também se tenta desvincular a civilização sulista de qualquer influência de Cuiabá e enfatizar a presença de um contingente populacional oriundo de outros estados da federação. $\mathrm{O}$ sul teria sido ocupado por grupos populacionais vindos de Minas Gerais, de São Paulo e do Rio Grande do Sul, além de imigrantes estrangeiros, sejam paraguaios ou de outros continentes. A essa origem são atribuídas diferenças marcantes, como a disposição para o trabalho e a associação atávica à modernização.

Após estabelecer um contraste com os povos do centro e do norte de Mato Grosso a partir da negação do que eles simbolizam, no segundo bloco de representações, são explicitadas as características constitutivas dos povos do sul. Pode-se perceber que "é desde logo notável a negação do papel do indígena na formação histórica da região" (Queiroz, 2006, p. 163). De fato, além de não aparecer explicitamente no discurso da geração de 1930, os povos nativos da região são deliberadamente excluídos do imaginário histórico: nos documentos da década de 1930 o que se lêe que "os atuais descendentes dos primeiros invasores ocuparam terras virgens, que os espanhóis abandonaram ante a batida paulista, dois séculos antes" (Queiroz, 2006, p. 163). Além disso, há a afirmação de que os migrantes mineiros fundaram a cidade de Santana do Paranaíba no deserto. Este tipo de interpretação encontra ressonância no chamado "pensamento 
abissal" (Santos, 2007), que fundamenta tanto o movimento simbólico para a exclusão dos indígenas do imaginário histórico, como o pretenso direito legal dos chamados pioneiros sobre a propriedade:

A zona colonial é, par excellence, o universo das crenças e dos comportamentos incompreensíveis que de forma alguma podem considerar-se conhecimento, estando, por isso, para além do verdadeiro e do falso.... Com base nas suas refinadas concepções de humanidade e de dignidade humana, os humanistas dos séculos XV e XVI chegaram à conclusão de que os selvagens eram sub-humanos. A questão era: os índios têm alma? Quando o Papa Paulo III respondeu afirmativamente na bula Sublimis Deus, de 1537, fê-lo concebendo a alma dos povos selvagens como um receptáculo vazio, uma anima nullius, muito semelhante à terra nullius, o conceito de vazio jurídico que justificou a invasão e ocupação dos territórios indígenas. Com base nestas concepções abissais de epistemologia e legalidade, a universalidade da tensão entre a regulação e a emancipação, aplicada deste lado da linha, não entra em contradição com a tensão entre apropriação e violência aplicada do outro lado da linha. (Santos, 2007, pp. 8-9)

Por conseguinte, na linha de raciocínio abissal construída pela geração de 1930, se as terras estavam vazias, a consequência lógica esperada é a valorização do pioneirismo. $\mathrm{O}$ espírito pioneiro e protetor das fronteiras nacionais é ressignificado como elemento constitutivo dos povos do sul. O pioneiro é ideologicamente valorizado como aquele que encontrou um deserto vasto nas terras sulistas e as transformou numa opulenta manifestação de modernidade, de civilização e de desenvolvimento. A estes atribuem, inclusive, o modo de se fazer política pelas armas como um dever cívico. Nesse sentido, ao pioneirismo junta-se a política por meio das armas como critérios de mando nos argumentos dos divisionistas da década de 1930.

Afinados, portanto, às ideias modernistas que pululavam entre a intelectualidade brasileira (Ortiz, 1988; Schwarcz, 1993), passam a pronunciar-se, não raro em viés racista; "chega-se mesmo a mencionar com orgulho a eugênica mocidade do sul" (Queiroz, 2006, p. 165). Além disso,

No tocante a essa apropriação de elementos da identidade já construída, o que mais se destaca são os esforços dos sulistas no sentido de rechaçarem qualquer pecha de barbárie e se afirmarem a si próprios como civilizados, modernos e economicamente desenvolvidos. (Queiroz, 2006, p. 164)

Isso fica claro no jogo de oposições em que colocam o sul como dinâmico e civilizado e o centro/norte como estatista e decadente. São, portanto, destas 
${ }^{10} \mathrm{O}$ principal parque do estado e ponto turístico de Campo Grande, fundado em 1993, por exemplo, é denominado Parque das Nações Indígenas e exibe uma imponente estátua de um guerreiro Guaicuru. representações cunhadas pela Liga Sul-mato-grossense desde a década de 1930 que se depreende o núcleo histórico das representações que os homens de letras de Mato Grosso do Sul trarão à tona na conformação da identidade sul-mato-grossense após a criação do estado. Como consequência, as visões de um indígena como reminiscência anacrônica e avessa à civilização se espraia nos discursos, encontrando pontes com a retórica contemporânea. Ademais, os nativos historicamente são vistos como inimigos dos homens sul-mato-grossenses, que, em verdade, estiveram "sujeitos aos constantes assédios dos índios e aos ataques de bandoleiros" - um dos cernes do que Banducci (2009, p. 107) caracteriza como a ideologia da cultura sul-mato-grossense.

Por outro lado, os indígenas são erguidos como símbolos do povo de Mato Grosso do Sul ${ }^{10}$. Pode parecer uma contradição, mas em uma análise mais detida percebe-se que o indígena é retomado de forma idealizada e relegada a um passado idílico, inexistindo como cidadão - isto é, destituído de seus direitos - na contemporaneidade (Banducci, 2009). Recupera-se, nesse contexto, a suposição de que o conteúdo opinativo veiculado na imprensa sul-mato-grossense, em especial em seu principal periódico, o Correio do Estado, aciona como quadro de referência primário os referenciais simbólicos e culturais afeitos à ideologia da cultura sul-mato-grossense (Banducci, 2009) quando em pauta estão os chamados conflitos indígenas.

\section{O SE QUE DIZ NOS JORNAIS SOBRE OS CONFLITOS: DOS EDITORIAIS}

Os editoriais publicados no período que compõe o recorte empírico desta investigação acompanham o decorrer da cobertura dos fatos apresentados nos itens informativos - ou seja, nas notícias e nos relatos factuais do conflito eclodido no final de agosto de 2015 na porção sul de Mato Grosso do Sul. No início, logo no dia 28 de agosto, véspera do assassinato do indígena Semião Vilhalva, identifica-se um editorial - "Sem Luz no Fim do Túnel" (2015) - cuja intenção principal é prevenir sobre uma possível consequência catastrófica. $\mathrm{O}$ título evidencia um tom fatalista e alarmante, sugerindo que não se vislumbra solução para o conflito entre fazendeiros e indígenas. Nesse primeiro momento, salienta-se que o posicionamento editorial assume as vozes dos proprietários rurais explicitamente como fonte veraz de informações, suficiente para a caracterização dos fatos.

No conflito mais recente, que teve início no último fim de semana, no município de Antônio João, distante 282 quilômetros da capital, na fronteira com o Paraguai, cinco fazendas foram invadidas por índios da etnia guarani kaiowa. Ao todo, 
segundo os proprietários, são aproximadamente 10 mil hectares de áreas ocupadas e reivindicadas. (“Sem Luz”, 2015, p. 2)

Mais à frente, a voz dos produtores rurais é novamente evocada na caracterização e julgamento moral (c) de personagens envolvidos.

“Terceiros interessados” no conflito, como é o caso, por exemplo, do Conselho Indigenista Missionário (Cimi), vinculado à igreja católica, em vez de apagar o incêndio que já dura décadas, jogam ainda mais gasolina nas chamas. Os produtores rurais de Antônio João, conforme informação publicada na edição de ontem do Correio do Estado, são categóricos em afirmar que o grupo católico atua diretamente nas invasões, criando condições para que elas ocorram. Logo a igreja, que em outros séculos chegou a ser lembrada justamente pela exploração de povos indígenas. (“Sem Luz", 2015, p. 2)

Em nenhum momento, outra voz, senão a dos produtores rurais, é acionada a fim de oferecer um contraditório ou relativizar as posições. Logo, portanto, nesse primeiro texto observa-se a política editorial do veículo refletindo a política de opinião dos produtores rurais, sistematizada principalmente por entidades que os representam, a exemplo da Federação de Agricultura e Pecuária de Mato Grosso do Sul (Famasul). Sobre o primeiro editorial, pode-se ainda afirmar que se destaca por introduzir os personagens e as funções de enquadramento que persistirão e se conformarão nos demais textos. Os indígenas, os proprietários rurais, o governo federal e terceiros interessados (Cimi e Igreja Católica) são os personagens integrantes da narrativa. Os termos que os (des)qualificam são, respectivamente, "invasores", “invadidos", "incompetente e ausente" e "jogam gasolina na chama" (incentivadores de invasões). O problema (a) apresentado no texto são os conflitos entre fazendeiros e indígenas, causados (b) pelas invasões de terra executadas pelos indígenas e fomentadas pelos terceiros interessados. Outro problema (a) é a não intervenção do governo federal no conflito, que seria responsável pelo tom fatalista e desesperançoso do título do editorial.

Nos três editoriais seguintes, dos dias 30 de agosto, 4 e 20 de setembro de 2015, a intenção é reforçar o entendimento de que o governo federal é o grande responsável pelos conflitos: "A ausência sentida nesse conflito é justamente de quem mais poderia agir para que ele cessasse: o Governo Federal" ("Silêncio Ensurdecedor”, 2015, p. 2); “Enquanto isso, até agora, não há qualquer indício de que o Governo Federal cumpra a promessa de solucionar o impasse das ocupações de terras por indígenas em Mato Grosso do Sul” (“Tudo na Mesma”, 
2015, p. 2). Dessa forma, os argumentos buscam estreitar a relação causal (b) entre conflito de terra e incompetência administrativa do governo federal:

O índio, tutelado pela União, e os proprietários de terra, que usam como principal argumento no embate o direito à propriedade, estão abandonados pelo seu principal mediador. Este conflito no interior de Mato Grosso do Sul é mais um exemplo da desorganização do Governo Federal, que lida com as demandas de seus cidadãos na fronteira da mesma maneira desastrosa que atua na economia: ampliando uma crise em vez de atuar para mitigá-la. (“Silêncio Ensurdecedor”, 2015, p. 2)

No excerto anterior, assim como em outras passagens dos textos, nota-se uma ampliação das definições e o estabelecimento de relações entre personagens. $\mathrm{O}$ indígena agora é também tutelado pela União e, portanto, mantém uma relação com o governo federal. Este, por sua vez, é concretizado no discurso também pela Fundação Nacional do Índio (Funai), sugerindo uma cumplicidade entre esses dois personagens. O Cimi e a Famasul são estabelecidos como representantes legítimos dos dois lados envolvidos no conflito. Por conseguinte, a posição editorial afasta-se, no plano retórico, da política de opinião da Famasul. A estreita sintonia entre política editorial e política de opinião dos proprietários rurais, evidente no primeiro editorial, agora não se pronuncia, mas ainda está presente de forma implícita: ao estabelecer os polos da disputa, de um lado, a Famasul e os proprietários rurais, com direito à propriedade, e, de outro lado, os indígenas, o governo federal e o Cimi; em seguida, ao atribuir a responsabilidade pelos conflitos ao governo federal. A posição editorial, destarte, indica o primeiro lado como vítima, sujeito passivo da ação do segundo bloco de personagens, o qual seria responsável pelas contendas e pela falta de solução.

Nesses três editoriais percebe-se, ainda, a ampliação das funções de enquadramento. A proposição de soluções (d) aparece de forma clara: a solução é a intervenção federal mediante "atitudes mais enérgicas e resolutivas" ("Expectativa Frustrada", 2015, p. 2), o cumprimento da reintegração de posse e a "aprovação da PEC 71, que fixa indenização aos donos das terras que foram demarcadas como reservas indígenas a partir do dia 5 de outubro de 2013" ("Tudo na Mesma”, 2015 , p. 2). À definição do problema (a) são acrescentados termos-chave que conformam o enquadramento: "batalhas de uma guerra que já dura décadas" e "bomba que está prestes a explodir"; assim como às causas (b):

Grande parte do conflito agrário entre índios e produtores nasceu da política do governo federal; na época, personalizado pelo Serviço de Proteção ao Índio (SPI), com demarcação de terras indígenas, verdadeiras colônias agrárias, que delimitaram 
o espaço das comunidades. Do outro lado, muitas áreas foram vendidas a produtores de boa-fé, passando para outras gerações que, agora, enfrentam o problema criado há décadas. ("Expectativa Frustrada”, 2015, p. 2)

No dia 14 de outubro de 2015, é publicado o editorial "Duas CPIs, Pouca Ação", cuja intenção central é estabelecer uma crítica à criação de duas comissões parlamentares de inquérito (CPI) na Assembleia Legislativa de Mato Grosso do Sul. Tal publicação é uma tentativa de defender um ponto-chave do enquadramento apresentado pelo Correio do Estado, que, naquele momento, enfrentava um contra-argumento factual. Desde o início da cobertura jornalística, os editoriais se erigiram insistindo que a causa central do conflito é o governo federal, por incompetência, inércia ou descumprimento de promessas. No entanto, a criação de uma CPI para investigar o envolvimento do Cimi - inciativa de deputados representantes dos proprietários rurais - e outra para apurar a responsabilidade do governo estadual no genocídio de indígenas entre os anos de 2000 e 2015 - esta como resultado da mobilização de deputados ligados às causas indígenas - atinge em cheio o ponto central do enquadramento proposto pelos editoriais até então. A criação das CPI desloca a responsabilidade pelos conflitos do plano federal para o plano estadual. Em outros termos, o que até esse ponto da cobertura era atribuído ao governo federal - o acirramento do conflito entre fazendeiros e indígenas - passa a ser corresponsabilidade dos terceiros interessados e do governo estadual. Em termos retóricos, a criação das CPI na Assembleia constrói-se como uma espécie de confissão de culpa dos grupos diretamente envolvidos no conflito. A intenção do editorial, diante dessa circunstância, consiste em desqualificar as duas CPI, insistindo que elas estariam desviando os esforços e gerando ações inócuas; e, consequentemente, tentar preservar o núcleo de sua interpretação causal.

A Tabela 1 sistematiza as funções de enquadramento (Entman, 1991, 1993) identificadas nos editoriais do jornal Correio do Estado durante o período adotado como recorte empírico da pesquisa.

$\mathrm{O}$ enquadramento exibido nos editoriais oferece uma narrativa básica em que a posição da empresa jornalística se evidencia logo no primeiro texto. Os personagens envolvidos e os julgamentos que os caracterizam, a definição do problema e a sinalização das explicações causais são apresentados. Nos demais textos publicados, observa-se um refinamento da caracterização dos personagens (muitas vezes oscilando julgamentos) e das explicações causais, além da proposição de soluções. De maneira geral, tal como expõe a Tabela 1 , o enquadramento propõe que o conflito se estabelece entre produtores rurais - caracterizados sempre com termos neutros, positivos ou vitimizadores - e 
os demais personagens - qualificados, pelo menos uma vez, negativamente. Como demonstrado, chega-se a estabelecer, implicitamente, uma relação de cumplicidade entre governo federal, Cimi e indígenas. No entanto, estes últimos sempre são colocados numa posição de inferioridade, pois são supostamente manipulados, tutelados e induzidos a agir.

\section{Tabela 1}

Funções de enquadramento presentes nos editoriais do Correio do Estado

Funções de enquadramento

$\begin{array}{ll}\text { a) problema } & \begin{array}{l}\text { Conflito entre indígenas e proprietários rurais; não intervenção } \\ \text { do governo federal. }\end{array} \\ \text { b) causa } & \begin{array}{l}\text { Incompetência do governo federal; incitação do conflito por } \\ \text { terceiros interessados; política do SPI de criação de reservas e } \\ \text { distribuição de terras no estado. }\end{array} \\ \text { c) julgamento moral } & \begin{array}{l}\text { Indígenas: invasores, tutelados pela União, manipulados, } \\ \text { abandonados pelo governo federal; }\end{array} \\ & \begin{array}{l}\text { Proprietários rurais: invadidos, produtores de boa-fé, } \\ \text { abandonados pelo governo federal; }\end{array} \\ \text { Governo federal, Funai, governo Dilma: incompetente, } \\ \text { desorganizado; } \\ \text { Cimi, Igreja católica: terceiros interessados, provocadores, } \\ \text { exploradores do passado que defendem explorados, } \\ \text { representantes dos indígenas. } \\ \text { Intervenção enérgica e resolutiva do governo federal; } \\ \text { reintegração de posse; aprovação da PEC 71. }\end{array}$

Nota. Elaborado pelos autores.

No apontamento das causas do conflito, nota-se um deslocamento da responsabilidade dos personagens diretamente envolvidos para um ente longínquo, no caso, o governo federal. Tal movimento esvazia a discussão sobre os atos de fazendeiros e indígenas. Num vértice retórico, o assassinato de Semião Vilhalva é apenas um dado, uma consequência lógica. A reunião e a deliberação de fazendeiros, que decidem usar os próprios meios para retomar uma fazenda, são vistos como uma ação natural e esperada. Esse ponto de vista é constantemente reforçado pela enumeração de conflitos anteriores, asseverando, pela repetição, a naturalização de atos violentos. Para efeitos de contextualização, em meados de 2015, o governo federal enfrentava uma crise econômica e política pronunciadas. A presidente Dilma Rousseff era alvo de uma série de críticas sobre a condução da economia, além de uma oposição contundente no 
parlamento, alimentada, principalmente, pelos desdobramentos dos escândalos de corrupção divulgados nos meios de comunicação em todo o Brasil. Em Mato Grosso do Sul, o jornal Correio do Estado assumia o mesmo tom de críticas ao governo federal. Esse contexto fornece os elementos principais constituintes do enquadramento construído para a compreensão dos conflitos que eclodem no longínquo município de Antônio João, na fronteira sul com o Paraguai.

$\mathrm{Na}$ construção do argumento central do enquadramento proposto pelos editoriais, observa-se, portanto, uma estratégia retórica que tem por objetivo restringir as possibilidades causais e explicativas. $O$ texto parte de uma assertiva que poderia ser válida, ao menos conjunturalmente, em outro contexto, para tornar aceitável uma explicação causal que não teria força explicativa sem a aceitação da primeira assertiva. A assertiva válida: "o Governo Federal é incompetente na gestão da economia do país"; assertiva restritiva: "o Governo Federal é incompetente para solucionar o conflito entre indígenas e proprietários rurais". A repetição dessa associação nos vários editoriais publicados no período completa a construção de um jogo de forças, tendo em vista que funciona com base no esquecimento de que não se explicou aquilo de que se fala: os motivos dos conflitos ${ }^{11}$. Ou seja, do ponto de vista retórico, a vinculação entre incompetência econômica e incompetência na solução dos conflitos fundiários encerra a discussão num quadro de referência compartilhado: gestão/administração. Todo e qualquer problema na economia é posto como uma questão de equalização eficiente e eficaz por meio da racionalização das ações dos agentes, conscientes dos meios disponíveis e dos fins almejados. Da mesma forma, os conflitos entre fazendeiros e indígenas seriam supostamente solucionados pela administração dos interesses em jogo. O enquadramento construído negligencia fatores da disputa simbólica que encontram suas fundamentações no campo dos valores e das tradições para cuja solução nada, ou muito pouco, concorrem medidas de gestão, puramente administrativas.

O quadro de referência tem sua origem, significado e articulação simbólica (Carvalho, 2009; Goffman, 2012) afeitos a um plano político-administrativo mais amplo e encontra sua legitimidade numa polarização político-partidária que não se relaciona diretamente com os conflitos entre indígenas e proprietários rurais. Nesse plano, os interesses, crenças e a visão de mundo de um dos lados em conflito, no caso os proprietários rurais, encontra maior ressonância na posição assumida pelo jornal estudado. O enquadramento construído a partir do quadro primário de referência alicerçado na dicotomia político-administrativa permite um acordo entre o sujeito midiático - a empresa jornalística Correio do Estado e os atores extramidiáticos - predominantemente os proprietários rurais - no estabelecimento de um enredo verossimilhante (Sodré, 2009). Denomina-se de enquadramento restritivo porque ofusca as complexidades envolvidas nos
${ }^{11}$ Etnograficamente falando, faz-se preciso registar que o acirramento do conflito decorre de experiências concretas vivenciadas em Mato Grosso do Sul nos últimos trinta anos. 
${ }^{12} \mathrm{O}$ Artigo 231 da Constituição Brasileira de 1988 e seus sucessivos parágrafos expressa o reconhecimento aos indígenas de sua organização social, costumes, línguas, crenças e tradições, e os direitos originários sobre as terras que tradicionalmente ocupam, competindo à União demarcá-las, proteger e fazer respeitar todos os seus bens. Por sua vez, o Artigo $67 \mathrm{da}$ mesma Carta Magna destaca que "a União concluirá a demarcação das terras indígenas no prazo de cinco anos a partir da promulgação da Constituição" (Brasil, 1988). conflitos entre fazendeiros e indígenas em Mato Grosso do Sul. No entanto, o argumento não resiste ao imperativo dos fatos. Quando duas CPI regionais são instituídas para investigar as responsabilidades dos personagens locais, a fragilidade do enquadramento se manifesta e uma contradição se estabelece. A verossimilhança esvai-se na parcialidade, na insuficiência e na restrição ao posicionamento de uma das partes envolvidas no conflito.

Concernente ao contexto que ilumina a análise, a conformação de enquadramentos midiáticos relacionados ao que Banducci (2009) caracteriza como ideologia da cultura sul-mato-grossense, a construção apresentada nos editoriais do jornal Correio do Estado não se forma a partir de uma identidade contrastiva em que a legitimidade de um nós contra um eles se baseia em elementos diacríticos que definem o ser sul-mato-grossense. O plano semântico em que se insere o enquadramento diz respeito, antes, à dicotomia político-administrativo-partidária representada, grosso modo, pela polarização situação-governo federal/oposição-governo estadual, em que o nós localiza-se no segundo polo e o eles no primeiro. Porém, na contramão da Constituição da República Federativa do Brasil de 1988, que reconheceu os direitos originários aos indígenas, a exemplo do direito às terras tradicionalmente ocupadas ${ }^{12}$, a ocultação da cidadania das etnias indígenas, marca decalcada na identidade forjada desde a geração de 1930, encontra uma vez mais vazão no silenciamento da política de opinião estudada.

\section{O QUE SE DIZ NOS JORNAIS SOBRE OS CONFLITOS: DAS COLUNAS}

Entre as colunas, considera-se no recorte empírico da pesquisa os artigos de membros da sociedade civil convidados ou espontaneamente enviados ao jornal cuja temática gira, direta ou transversalmente, em torno dos problemas concernentes aos conflitos entre proprietários rurais e indígenas. Em tese, esses artigos têm o papel fundamental na promoção do debate e ampliação do conhecimento sobre determinado tema quando há uma real recepção de ideias, posições, argumentos e pontos de vista polifônicos e polissêmicos, nos quais se promove ou não o verdadeiro debate público. No Correio do Estado, as colunas ocupam posição de destaque, localizadas na página 2, ao lado dos editoriais. Para efeitos deste artigo, foram selecionados cinco artigos assinados por representantes da sociedade civil sul-mato-grossense.

Nesse ínterim, duas colunas do psicanalista Valfrido Chaves são de significativa pertinência na demonstração dos argumentos acerca da relação entre enquadramentos jornalísticos e a ideologia da cultura sul-mato-grossense. O texto “Colonização à Brasileira”, datado do dia 28 de agosto de 2015, curiosamente 
é uma republicação ${ }^{13}$ que antecede o assassinato de Semião Vilhalva e, assim, juntamente com o editorial do mesmo dia, encerra o quadro geral a partir do qual se pretende definir o acontecimento jornalístico "conflito entre indígenas e produtores rurais". O segundo texto, "Conflito Indígena, o Judiciário e o 'Caraí” complementa o primeiro, ampliando as funções de enquadramento.

O título "Colonização à Brasileira" remete a um plano semântico ancorado na história da ocupação do território e na suposta submissão à vontade do elemento introduzido. A adjetivação com a locução "à brasileira” exprime uma idiossincrasia, uma singularidade, da forma de colonização realizada no Brasil - tal como se diz de uma receita culinária, um modo de preparar típico do brasileiro. Fornece, desse modo, um tom irônico que se deslinda no decorrer do texto a partir da introdução dos personagens, da polarização estabelecida e da definição das funções de enquadramento. A mesma polarização verificada nos editoriais se acentua e se refina com a introdução de adornos, perfazendo uma moldura talhada, esculpida, pelo requinte de uma linguagem incisiva e eficaz na definição dos quadros de referência acionados. Na caracterização dos personagens que emergem no discurso, é explicitado o sentido moral da polarização estabelecida.

No polo positivo, encontram-se os produtores rurais. São os "pioneiros", "ex-combatentes (da Guerra do Paraguai)", povo tenaz e de fibra que viveu uma "história árdua, muitas vezes violenta, em que a solidão e a falta de recursos eram soberanas" (Chaves, 2015a, p. 2). Mais tarde vieram os "sulistas", "sangue novo, com vocação para o trabalho árduo com a terra e a produção agrícola”. O produtor é o "bode expiatório", são os "brasileiros dignos que vivem para o trabalho e suas famílias", expulsos de terras "legítimas". No polo negativo localizam-se os agentes do Estado. Esse personagem da narrativa é concretizado na figura dos procuradores federais sectários, "militantes", representantes de "um projeto de poder no qual a luta de classes deve ceder lugar à promoção do conflito étnico e racial entre brasileiros". Sob a influência do polo negativo encontram-se os indígenas, entendidos como povos atrasados, à margem do "progresso" e do "desenvolvimento"; "indigentes", "alcoólatras", "terroristas", "sem perspectiva”, submetidos ao "trabalho escravo", enredados na "prostituição", "estupros e impunidade". Ainda há, nas palavras do autor, "índios latifundiários". Mas os indígenas são também vitimizados, pois "forças escusas" agem "promovendo manipulações político-ideológicas”.

O problema (a) apresentado no texto é a expulsão dos pioneiros de suas propriedades legítimas e, por seu turno, a interpretação da própria Constituição. Essa expulsão é vista como crime coletivo, perpetrado por índios, influenciados por forças escusas e sob a conivência estatal. A causa (b) do problema seria uma
${ }^{13}$ Segundo informação do próprio jornal, o texto foi originalmente publicado uma década antes. 
Indústria de conflitos e invasões que quer semear ódios definitivos entre índios e pioneiros, sob o olhar conivente do aparelho estatal, quando procuradores federais "defendem índios", mas, sectariamente, esquecem que a Constituição é um todo em que a etnia não determina privilégios ou culpas inatas. (Chaves, 2015a, p. 2)

Ao lançar mão de termos-chave como "pioneiros", "vocação" e "trabalho" ("com vocação para o trabalho"), "tenacidade" e "fibra", o autor define os traços psicossociais e comportamentais dos que seriam os legítimos colonizadores, sempre em contraposição aos "tutelados", "indigentes" e "terroristas" que, de fato, sob a proteção dos "militantes" da esfera estatal, estariam ocupando a terra. Uma oposição estruturante se estabelece, portanto, entre, de um lado, a colonização como livre iniciativa, empreendedorismo e, de outro, a colonização tutelada pelo Estado "à brasileira”.

Em segundo texto publicado pelo mesmo autor, no dia 29 de setembro de 2015, portanto um mês após o primeiro artigo, nota-se a reafirmação dos principais pontos. No entanto, se no primeiro a intenção era apresentar um quadro inicial e amplo por meio do qual se enunciavam as formas básicas da definição do problema, das causas e dos julgamentos morais, no segundo o cerne é a exortação da neutralidade do Poder Judiciário como proposição de solução (d) para o dissenso (Chaves, 2015b, p. 2).

A estratégia retórica adotada é a comparação da ação do Judiciário com a função do Caraí entre os povos indígenas. Segundo o autor, os povos que habitavam o território brasileiro quando da chegada dos portugueses viviam em diferentes grupos e aldeias, ora aliados, ora inimigos. As relações entre esses diferentes grupos obedeciam a uma série de regras. A desobediência a essas regras de convívio poderia levar a conflitos. Nesse "universo guerreiro", o Caraí era o indivíduo que não pertencia a nenhuma linhagem guerreira e por isso circulava entre os diversos grupos, agindo como guia para a "Terra sem mal" e como promotor da paz. Caberia ao Poder Judiciário assumir sua "função Caraí" e reestabelecer o estado de direito e democrático que, no entender do articulista, estava rompido pela condição beligerante estabelecida entre indígenas e proprietários rurais. Isso aconteceria porque os "ingênuos" indígenas seriam manipulados por interesses ideológicos e fisiológicos de agentes de fora e de dentro do aparelho estatal.

No primeiro texto, os indígenas estavam posicionados próximo ao polo negativo, junto dos agentes manipuladores. $\mathrm{O}$ enquadramento sugerido colocava-os como estranhos, diferentes dos pioneiros, dos desbravadores, tenazes e vocacionados sul-mato-grossenses: os proprietários rurais. No segundo texto, a estratégia é reposicionar os indígenas. Agora são "brasileiros que podiam estar 
lado a lado", injustiçados historicamente pelos colonizadores europeus, desde que não obnubilados por ideologias exógenas (o polo negativo é identificado como a "esquerda radical").

Na sequência, o texto intitulado "Cuidado com a fronteira!" (Mendes, 2015), assinado pelo presidente da Comissão Local de Assuntos Agrários e Agronegócio da Ordem dos Advogados do Brasil (OAB-MS), de 2 de setembro de 2015, chama a atenção para um problema (a) derivado do conflito entre fazendeiros e indígenas: a segurança na fronteira. Segundo o autor, a causa (b) de sua preocupação seria a participação de "facções paraguaias" no conflito em Antônio João. Diante do fato, propõe (d) a intervenção das Forças Armadas brasileiras, alegando que recairia às autoridades constituídas a acusação de crime de responsabilidade caso não determinassem a intervenção militar imediata. Em seu argumento, eivado de citações de leis, evoca o patriotismo do tenente Antônio João (que, curiosamente, empresta o nome ao município onde naquele momento se estabeleciam os conflitos) na Guerra do Paraguai ao resistir, mesmo ciente de sua iminente derrota, às investidas do exército de Solano Lopes. Depois de afirmar que aos proprietários rurais é garantido o direito à "retomada", mais uma vez apoiando-se em uma leitura de fragmentos da Constituição e de leis ordinárias, termina por dizer que as "porteiras abertas a estrangeiros" estão fragilizando a soberania nacional.

Concernente à categoria analítica personagens, o que se verifica é a entrada em cena, agora de forma explícita, de "facções paraguaias" como incitadoras dos conflitos. O governo federal ainda comparece no discurso como grande responsável e inerte. Os proprietários rurais continuam como vítimas que têm o direito à "retomada" de suas terras. Nota-se uma busca por legitimação do enquadramento por meio do acionamento de quadros de referência que se constroem sobre uma dicotomia básica entre nacional/estrangeiro. A utilização de termos e expressões-chave como "defesa de fronteira", "estrangeiro", "segurança nacional" e "soberania nacional", conotando, em seguida, que o direito de "retomada" pelos proprietários rurais seria similar à garantia patriótica do território nacional, que estaria de "porteiras abertas a estrangeiros", assim como as porteiras das fazendas foram invadidas por indígenas. Oferece-se um amálgama entre conflitos de indígenas com produtores rurais e disputas fronteiriças entre brasileiros e paraguaios. Dessa forma, fica implícita a associação dos proprietários rurais aos "nacionais", ao nós, com direito de retomar a terra de facções estrangeiras, que por constituírem "facções" e por serem "estrangeiras" podem e devem ser repelidas com o uso da força. Conota-se, aqui, que a intenção é justificar o uso desproporcional da força por proprietários rurais nas ações do dia 29 de agosto de 2015, que culminaram na morte do indígena Semião Vilhalva. 
Nos textos do dia 3 e 16 de setembro de 2015, verifica-se uma abordagem explícita do artifício retórico de enquadramento dos conflitos. O jornalista e advogado Ruy Sant'Anna faz uma crítica ao governo da presidente Dilma Rousseff e do seu partido, o Partido dos Trabalhadores (PT), nos textos de nome "Lucro dos Banqueiros e a Pergunta: De Onde Tirar o Dinheiro?" e "Vida Desalinhada, Invasões Indígenas e Projeto Pró-Jaca”. Ressalta que medidas econômicas que ampliam impostos geram desemprego, inflação e aumento do rendimento dos bancos. Contribuem, ainda, para a desconfiança no governo, que, segundo o autor, deveria cortar gastos e não aumentar arrecadação com impostos. Nessa caracterização, ao governo federal associam-se as ações e os predicativos como "incompetente", "não deve ser perdoado", "mentiroso", "desfaçatez", "luminares brasileiros" (aqui, acentuando o tom irônico), "expandem a ganância irracional", autor (o governo federal) de "pedaladas e irregularidades orçamentárias" (Sant'Anna, 2015a) e "estelionato eleitoral" (Sant'Anna, 2015b). Afirma que o governo estaria lançando o "projeto jaca", "fruta enorme, com cheiro forte e de difícil digestão" (Sant'Anna, 2015b).

Após essa crítica veemente, introduz o outro personagem: os proprietários rurais. Esses são caracterizados como "os que carregam o país nas costas e a nação sobre seus ombros", "bravos e honestos" e "o que sofrem os produtores é humilhante e injusto":

Estes sempre foram e continuam sendo tratados injustamente, mesmo com uma representante do agronegócio no seio ministerial de Dilma. De ano a ano, aumentam as invasões indígenas em áreas rurais adquiridas de boa fé e tituladas pelo Governo. Os produtores não são invasores; são proprietários. Se houver alguma questão jurídica que seja desfavorável aos ruralistas, eles têm que ter sua terra adquirida pelo Governo e pagas com justiça, sobre todos os bens acrescidos sobre a terras que eram nuas, e, hoje, produzem. (Sant'Anna, 2015a, p. 2)

O excerto expõe não só o julgamento moral (c) dos personagens e suas posições nos conflitos, como sugere uma solução (d) para o problema: a "indenização justa" aos proprietários. Depreende-se que o quadro de referência acionado na definição do enquadramento dos fatos aproxima-se do esforço empreendido pelos editoriais publicados. Busca-se vincular a eventual incompetência do governo federal na gestão político-econômica com uma incapacidade de mediar e solucionar os conflitos entre indígenas e proprietários rurais em Mato Grosso do Sul. Tal interpretação exime as partes envolvidas de responsabilidade pelos seus atos e, ao mesmo tempo, desloca a força explicativa de uma assertiva previamente compartilhada e aceita para uma assertiva cuja pretensão é encerrar o enquadramento dos fatos. 
O enquadramento geral acentua a polarização apresentada nos editoriais, principalmente vinculando atributos morais aos personagens envolvidos. Fica clara uma delimitação entre o bem e o mal, o certo e o errado. Todavia, a composição dos polos antagônicos varia. Observa-se uma ambiguidade na caracterização e no posicionamento dos indígenas que segue desde a mais contundente desqualificação moral até a comiseração e a indulgência. Ora os indígenas são posicionados junto ao governo federal, às "facções terroristas", aos "militantes", aos "grevistas", aos "sem-terra"; ora são deslocados para o campo dos inocentes e vitimados por ações dos "maus". Para efeitos de sistematização, a Tabela 2 apresenta as funções de enquadramento (Entman, 1991, 1993) identificadas nas colunas analisadas do jornal Correio do Estado.

\section{Tabela 2}

Funções de enquadramento nas colunas de opinião do Correio do Estado

\section{Funções de enquadramento}

a) problema

Conflito entre indígenas e proprietários rurais; não intervenção do governo federal; invasão estrangeira; instabilidade social; segurança nacional; invasão de propriedade privada.

b) causa

Incompetência e fraqueza do governo federal; incitação do conflito por "terroristas-comunistas-leninistas" e facções paraguaias; defesa da propriedade privada.

c) julgamento moral

Indígenas: invasores, destruidores selvagens, atrasados, indigentes, alcoólatras, protegidos pela União, por comunistas e por terroristas, agem como grevistas e sem-terra, caboclos, latifundiários; por outro lado são manipulados, abandonados pelo governo federal;

Proprietários rurais: invadidos, produtores de boa-fé, abandonados pelo governo federal, carregam o Brasil nas costas, corajosos, desbravadores do sertão inóspito, arrojados, intrépidos, humilhados, injustiçados, bodesexpiatórios, pioneiros, dignos, trabalhadores, excombatentes da guerra do Paraguai, povo tenaz e de fibra;

Governo federal (Funai, governo Dilma, PT): incompetente, corrupto, fraco, comunista, mentiroso, pseudointelectuais;

Poder Judiciário: mediador, pacificador.

d) proposição de solução Intervenção enérgica e resolutiva; reintegração de posse; desapropriação com indenização justa dos fazendeiros.

Nota. Elaborado pelos autores. 
No polo negativo, o que se observa é a ampliação dos quadros de referência acionados. Nos editoriais se deslindou uma moldura político-administrativa da qual derivam adjetivos como "incompetente", "desorganizado" e "inoperante". Nos artigos, como demonstra a sistematização da Tabela 2, o elemento político-ideológico é acentuado ao rotular o governo federal de "comunista", "leninista" e "marxista"; e ao apresentar agentes públicos, no caso membros do Ministério Público Federal, como "militantes”. Ademais, há a menção vaga a "terroristas” como simples alavanca capaz de fechar o quadro de referência proposto. A eloquência das qualificações se pronuncia, nos casos analisados, como um apelo emocional ao leitor a fim de mobilizá-lo na aceitação de uma proposição que, na verdade, não explica os fatos.

No polo positivo, a miríade de termos-chave leva a um quadro de referência afeito à ideologia da cultura sul-mato-grossense. É na caracterização dos proprietários rurais que surgem os mesmos atributos abissais (Santos, 2007) que definem a identidade de Mato Grosso do Sul forjada desde os anos 1930. Os elementos diacríticos que permitem dizer quem compõe o ser sul-mato-grossense são alçados à condição de qualidades morais que legitimam o ponto de vista dos proprietários rurais na definição dos fatos. Dizer que são pioneiros, arrojados, trabalhadores, desbravadores do sertão inóspito e ex-combatentes confere autenticidade, justifica o direito de mando e a ideologia da classe de proprietários rurais no discurso histórico que, quando retomado, no momento de adensamento das contradições sociais, revela, por outro lado, a fragilidade e a artificialidade desse mesmo discurso. A necessidade de reiteração dos atributos a cada conflito deflagrado revela a crise da forma de dominação tradicional que, aos olhos dos dominadores, ainda são suficientes para justificar a submissão e recato da população indígena do estado de Mato Grosso do Sul. A despeito da descrença dos dominados, o enquadramento que toma como referência elementos de uma ideologia da cultura presta-se a convencer os próprios dominadores do direito de exercer o domínio e, consequentemente, a justificar o uso desproporcional da força nos conflitos.

Constitui-se um enquadramento que aciona vários quadros de referência ou níveis composicionais. Isto é, um nível presente ou imediato: a incompetência na gestão da crise político-econômica, que se constrói na articulação dos conflitos entre indígenas e proprietários rurais com temas que são contemporâneos e mobilizam a opinião pública e, por isso mesmo, são tratados, concomitantemente, pelos diversos meios de comunicação. E um nível periférico: polarizações político-ideológicas que acionam referência à delimitação entre amigos e inimigos, nacionais e estrangeiros, um nós e um eles. Denota-se que a ideologia da cultura se apresenta como quadro latente de referência - de matriz histórica - ao qual se recorre para conferir legitimidade à construção retórica. 


\section{CONSIDERAÇÕES FINAIS}

Este estudo ressalta a necessidade de reflexão sobre o significado dos enquadramentos propostos nos textos em sua dinâmica de articulação da opinião pública com as opiniões publicadas e as políticas de opinião (Gomes, 2009) em disputa quando a temática circunscreve os povos indígenas e os seus conflitos com proprietários rurais em Mato Grosso do Sul. No jornal Correio do Estado, o principal veículo impresso do estado, observa-se desde o início da cobertura dos fatos, em 2015, a reboque do assassinato da liderança indígena Semião Vilhalva, um alinhamento retórico da política editorial com a política de opinião defendida, principalmente, pelos grupos que representam os interesses dos produtores rurais.

O primeiro editorial apresentado nesta análise é explícito na tomada de posição ao filiar-se, acriticamente, às percepções e opiniões dos proprietários rurais. Destes, toma para si as representações sobre os personagens envolvidos, principalmente indígenas e os movimentos sociais organizados. Essa afinidade política e ideológica fica evidente na definição das colunas de opinião veiculadas no jornal. Em sua maioria, os textos se aproximam da política de opinião dos representantes dos proprietários rurais. Os enquadramentos apresentados buscam legitimar argumentos valendo-se de estereótipos e de preconceitos, historicamente construídos e ideologicamente sedimentados num discurso identitário, eivado de julgamentos morais, acerca dos genuínos sul-mato-grossenses. Junto a argumentos racionais sobre direito de propriedade, princípios constitucionais e estado de direito, entre outros, projetam-se uma série de qualificações substanciais que funcionam como marcadores de pertença a estatutos sociais diferenciados. Em termos retóricos, na linha de um "pensamento abissal" (Santos, 2007), conota-se que os proprietários rurais seriam, ad infinitum, hierarquicamente superiores aos povos indígenas porque compartilham os atributos morais e constitutivos que definem o verdadeiro ser sul-mato-grossense.

O enquadramento proposto estabelece uma ponte entre opinião publicada e senso comum, estabilizando a realidade social (Sodré, 2009) na medida em que aciona elementos afeitos a uma ideologia da cultura sul-mato-grossense, nesse caso comparecendo como quadro de referência primário compartilhado não apenas pelo grupo de interesse, mas sobretudo (por isso a importância) difundido entre a comunidade de sentido (Gomes, 2009) à qual se dirigem os articulistas do jornal. Este quadro de referência primário, que penetra e molda os discursos veiculados no jornal, seleciona, silencia e exacerba características da realidade social e, sobretudo, indica o sentido e a forma como deve ser decodificada a realidade, porque é compartilhado e mobiliza-se para estruturar a experiência dos sujeitos envolvidos na ação (Goffman, 2012). É, portanto, na medida em 
que a ideologia da cultura sul-mato-grossense estrutura a experiência da vida cotidiana em Mato Grosso do Sul que se conforma eficientemente o discurso midiático local.

O jornal Correio do Estado não só tem sua sede e a maioria de seus leitores distantes aproximadamente 300 quilômetros da região do conflito, como também explicita um afastamento simbólico ainda maior da realidade vivida por indígenas no sul do estado. Consequentemente, o enquadramento dos fatos atravessados pelas mediações estudadas é, em parte, diverso daqueles hipoteticamente acionados nos contextos locais. Dessa forma, evidencia-se o papel da ideologia da cultura sul-mato-grossense no posicionamento do jornal: é uma matriz cultural que funciona como quadro de referência primário de uma comunidade de sentido que estabelece uma distinção simbólica entre indígenas e proprietários rurais que se pretende suficiente para justificar quem é o legítimo detentor das terras em Mato Grosso do Sul. Trata-se de um simples transbordamento do discurso identitário que define, a um só tempo, quem são os verdadeiros sul-mato-grossenses e quem tem o direito de mando na região, para um contexto de disputas em torno do direito à terra, cujos termos em contenda remetem aos preceitos constitucionais firmados na Carta de 1988.

Nesse sentido, as construções retóricas veiculadas no jornal Correio do Estado não favorecem o debate, o esclarecimento e a defesa de posições, mas, antes, a imposição de uma opinião previamente tomada como verdadeira e certa, cuja intenção é, tão somente, angariar adeptos apelando para um sentimento identitário preocupado em definir quem é o amigo e o inimigo, o nós e o outro, deturpando, por conseguinte, os termos do debate; isto é, transborda-se num espaço cerceado e dominado por um dos lados em disputa, articulando sua posição a partir de estereótipos e preconceitos, compartilhados, principalmente, pela elite tradicional e ruralista no estado. $\mathbf{M}$

\section{REFERÊNCIAS}

Amarilha, C. M. M. (2006). Os intelectuais e o poder: História, divisionismo e identidade em Mato Grosso do Sul [Dissertação de Mestrado, Universidade Federal da Grande Dourados]. Repositório do Programa de Pós-Graduação em História. https://bit.ly/3tvrWhf

Banducci, A., Jr. (2009). Tradição e ideologia: Construção da identidade em MS. In M. A. Menegazzo \& A. Banducci Jr. (Orgs.), Travessias e Limites: Escritos sobre identidade e o regional (pp. 107-134). Editora UFMS.

Bittar, M. (2009). Mato Grosso do Sul, a construção de um Estado (vol. 1). Editora UFMS. 
Carvalho, C. A. (2009). Sobre limites e possibilidades do conceito de enquadramento jornalístico. Contemporânea, 9(2), 1-15. http://bit.ly/3eSBwaa

Chaparro, M. C. (2008). Sotaques d'aquém e d'além mar: Travessias para uma nova teoria de gêneros jornalísticos. Summus.

Chaves, V. (2015a, 28 de agosto). Colonização à brasileira. Correio do Estado, 2.

Chaves, V. (2015b, 29 de setembro). Conflito indígena, o judiciário e o 'Caraí. Correio do Estado, 2.

Conselho Indigenista Missionário. (2016). Cartografia de ataques contra indígenas: Dossiê: Um genocídio em curso no Mato Grosso do Sul. https://caci. cimi.org.br.

Constituição da República Federativa do Brasil. (1988). Senado Federal.

Dal Moro, N. (2012). O pensar da elite sobre o povo comum: Espaço público, viver urbano e reterritorialização do centro da cidade de Campo Grande (décadas de 1960-70) [Tese de Doutorado, Pontifícia Universidade Católica de São Paulo]. Biblioteca Digital da PUCSP. https://bit.ly/3toNGLU

Duas CPIs, pouca ação. (2015, 14 de outubro). Correio do Estado, 2.

Entman, R. (1991). Framing U.S. coverage of international news: Contrasts in narratives of the KAL and Iran air incidents. Journal of Communication, 41(4), 16-27. https://doi.org/10.1111/j.1460-2466.1991.tb02328.x

Entman, R. (1993). Framing: Towards clarification of a fractured paradigm. Journal of Communication, 43(4), 51-58. https://doi.org/10.1111/j.1460-2466.1993. tb01304.x

Expectativa frustrada. (2015, 4 de setembro). Correio do Estado, 2.

Gitlin, T. (2003). The whole world is watching: Mass media in the making and unmaking of the New Left. University of California Press.

Goffman, E. (2012). Os quadros da experiência social: Uma perspectiva de análise. Vozes.

Gomes, W. (2009). Jornalismo, fatos e interesses: Ensaios de teorias do jornalismo. Insular.

Kuypers, J. (2009). Rhetorical criticism: Perspectives in action. Lexington.

Lopes, M. I. V. (2005). Pesquisa em comunicação. Loyola.

Martins, J. S. (2010). A sociabilidade do homem simples: Cotidiano e história na modernidade anômala. Contexto.

Melo, J. M., \& Assis, F. (2010). Gêneros jornalísticos no Brasil. Editora Umesp.

Mendes, P. P. (2015, 2 de setembro). Cuidado com a fronteira! Correio do Estado, 2.

Ortiz, R. (1988). A moderna tradição brasileira: Cultura brasileira e indústria cultural. Brasiliense.

Queiroz, P. R. C. (2006). Mato Grosso/Mato Grosso do Sul: Divisionismo e identidades (um breve ensaio). Diálogos, 10(2), 128-156. https://bit.ly/3rYU8ZL 
Sant'Anna, R. (2015a, 3 de setembro). Lucro dos banqueiros e a pergunta: De onde tirar o dinheiro? Correio do Estado, 2.

Sant'Anna, R. (2015b, 16 de setembro). Vida desalinhada, invasões indígenas e projeto pró-jaca. Correio do Estado, 2.

Santos, B. S. (2007). Para além do pensamento abissal: Das linhas globais a uma ecologia de saberes. Revista Crítica de Ciências Sociais, 78, 3-46. https:// doi.org/10.4000/rccs.753

Schwarcz, L. M. (1993). O espetáculo das raças: Cientistas, instituições e questão racial no Brasil, 1870-1930. Companhia das Letras.

Sem luz no fim do túnel. (2015, 28 de agosto). Correio do Estado, 2.

Silêncio ensurdecedor. (2015, 30 de agosto). Correio do Estado, 2.

Sodré, M. (2009). A narração do fato: Notas para uma teoria do acontecimento. Vozes.

Tudo na mesma. (2015, 20 de setembro). Correio do Estado, 2.

Artigo recebido em 27 de junho de 2020 e aprovado em 31 de janeiro de 2021. 